Порівняльна професійна педагогіка 5(3)/2015

Comparative Professional Pedagogy 5(3)/2015

DOI: $10.1515 / \mathrm{rpp}-2015-0048$

Doctor of Pedagogical Sciences, Full Professor, ALINA SBRUIEVA Sumy State Pedagogical University named after A. S. Makarenko, Ukraine Address: 87 Romenska St., Sumy, 40002, Ukraine

E-mail: sbruieva@gmail.com

\title{
INTEGRATION OF EDUCATIONAL AND RESEARCH CONSTITUENTS OF THE PROCESS OF SPECIALISTS' PROFESSIONAL TRAINING IN THE UNIVERSITIES OF DEVELOPED COUNTRIES
}

\begin{abstract}
In the article the characteristic of strategies of the integration of educational and research constituents of the process of specialists' professional training in the universities of developed countries has been given. The relevance of the problem in the context of requirements to the graduate represented in the European qualifications framework $(E Q F)$ and formulated in the Dublin Descriptor of the EQF has been proved. The conclusion has been made about the strategies of integration of educational and research activities of the university as a multilevel and multidimensional system of interconnected, interdependent, and interrelated components. The study proves that the systemic character of research-oriented strategies is achieved by an interrelation of activities at all levels of implementation, and the inclusion of these strategies into the others, directed at increasing efficiency of educational process (development of E-learning, flexible curriculum, formation of a single university educationalresearch community, development of the university campus as a broad educational environment, etc.). The strategies of solving research problem in the context of defining the mission of the higher education institution and its full realization; development of curricular and methodological foundations of research-oriented learning; development of research activity strategies aimed at integration of educational and research constituents of the process of specialists' training; professional staff development aimed at formation of readiness to research-oriented learning, and modernization of organizational structures of the university able to realize the mission of the university have been characterized.
\end{abstract}

Key words: university, educational activities, research activities, integration, researchoriented training, strategy, professional training.

\section{INTRODUCTION}

Addressing the problem of integration of educational and research activities of the university is quite traditional: since appearance of the so-called Humboldtian University, that is, the middle of the XIX century, classical higher education had the purpose of providing fundamental scientific knowledge, accompanied by research activities of teachers and students. In modern conditions of knowledge society, when the mission of the University includes both production of knowledge, its formation in the process of professional training, its dissemination, including the help of ICT, and use in innovative processes, the study of the highlighted problem is of particular relevance.

The necessity to consider the problem of integration of educational and research constituents in specialists' training we associate with the requirements of the European community to the higher school graduate, reflected in Framework for Qualifications of the 
European higher education area. The higher school graduate must be able to use creatively the latest knowledge in the professional sphere with the purpose of study and practical application of his own ideas; to diagnose the results of research in the professional sphere by integrating the information from different fields of knowledge and hypothesizing in conditions of limited information support; to demonstrate leadership qualities and innovative approaches to work and study in an unfamiliar, complex and unpredictable environment that requires problem solving by taking into account the numerous factors that interact with each other; to analyze the strategic visions of team work (Framework, 2005).

\section{THE AIM OF THE STUDY}

The aim of the study is to characterize institutional strategies for the integration of educational and research constituents of the process of specialists' professional training in the universities of developed countries.

\section{THEORETICAL FRAMEWORK AND RESEARCH METHODS}

The study is based on the conceptual provisions concerning the mission of the university in conditions of knowledge society (Murphy et. al, 2010; Wildavsky, 2010), according to which higher school is being transformed into a driving force of economic and social development of the society, thus ensuring its sustainable development and competitiveness in the global economic space.

The subject of the analyses in this context are the documents of the Council of Europe, European Commission of the EU, which express the conviction of the international scientific and expert community, politicians, employers, society in the whole in the necessity of modernization of higher education through integration of educational, research and innovative activities of European universities (Delivering, 2009; European Commission, 2014).

Problem analysis is impossible without addressing the fundamental and applied research of the theorists and practitioners of higher education, in which the analyzed problem is considered versatile and systemically. A certain confirmation of such judgment may serve the bibliography of research on the problem composed by the famous British researcher Mick Healey (Healey, 2010). This bibliography includes more than five hundred names, but is called "selected sources", i.e. actually the number of references to the problem is much more numerous. The subject of our analysis will be primarily the sources devoted to the generalization and systematization of institutional strategies of different levels of integration of educational and research activities aimed at the effective training of a specialist that is competitive in today's society (Baldwin, 2005; deWeert, 2004; Hénard, 2010; Jenkins and Healey, 2005; Robertson, 2007; Trowler and Wareham, 2007).

Finally, the conceptual approaches to the solution of the research problem are outlined in the documents defining the development strategy for universities in developed countries. Our attention, taking into account the specificity of the subject, attracted the websites of several British, Australian, Canadian and American universities, which contain detailed strategy for the integration of educational and research activities of the university in training specialists.

Research methods are the problem-topical analysis of the documents and researches on the problem under study, which identified a wide range of possible aspects of its consideration; terminological analysis, which is useful in the process of clarifying the essence of the approaches used in the universities in different countries to solve the problems that became the subject of the review; a method of systematizing the strategies of integration of educational and research activities of the university in training specialists. 


\section{RESULTS}

In the studies devoted to analysis of the ways of interconnection of educational and research activities of the university the following terms are generally used: teachingresearch nexus (Baldwin, 2005; Trowler and Wareham, 2007), research/teaching nexus, teaching and research nexus (deWeert, 2004); teaching and research link (Jenkins and Healey, 2005). In our view, to reflect the essence of the investigated phenomenon such terms as interrelation, correlation, interaction can be used to define the different levels and methods of involvement of the research constituent of specialists' professional training. In our study we use the term integration, which reflects the maximum degree of development of the investigated phenomenon and the process of its achievement. Another set of terms that are worthy of our attention in the context of the study, concerns the specific features of the educational process organization on the basis of integration of educational and research constituents. These include: research-informed teaching/learning, research-enhanced teaching/ learning, research-led teaching/learning, research-linked teaching/learning, research-infused teaching/learning, research-based teaching/learning, research-oriented teaching/learning, research-tutored teaching/learning, and others (Jenkins and Healey, 2005). As generalization of these we will further use the term research-oriented teaching/learning.

In the framework of implementation of the study objectives we have defined the organizational levels of integration of educational and research activities in the university, the subjects of these activities, the types and contents of strategies that are used in the universities of developed countries. The levels of implementation of such strategies and their subjects are: institutional (university), sub-institutional (educational and research departments of the university) and chair. Further we will characterize the above mentioned strategies according to the levels, subjects and types of their implementation.

Institutional strategies. To these strategies, that are political in nature and implemented by university bodies, belong the following:

- developing the documents that set the strategic priorities of the institution, especially its mission. In the development strategies adopted by the leading universities of the world there is a clear statement of the fact that the integration of educational and research constituents of the university activities is seen as the way of realization of its mission. An example of the deliberate focus on the development of the integration of education and research is, in particular, the universities of the USA and the UK, which take the leading places in the international rankings of the world universities. In particular, in defining the mission and core values of the University of Cambridge it is referred to "the close interrelationship between teaching, scholarship, and research" (University of Cambridge, 2015). California Institute of Technology announces itself to the world in this way: "Caltech is a world-renowned research and education institution focused on science and engineering, where faculty and students pursue new knowledge about our world and search for the kinds of bold and innovative advances that will transform our future" (California Institute of Technology, 2015). In Harvard College mission it is stated, that "beginning in the classroom with exposure to new ideas, new ways of understanding, and new ways of knowing, students embark on a journey of intellectual transformation" (Harvard College, 2015);

- application of methods of strategic and operational planning and institutional audit. Conducting the audit of the implementation of strategic and operational planning includes the development of a system of indicators that provide an opportunity to investigate the status of problem solution. Analysis of practice of the world's leading universities, in 
particular Sydney University (Australia) allowed the researchers to formulate criteria, that certify the implementation of university strategies of research-oriented learning:

(a) level of students' awareness of the necessity of their engagement in research work and their participation in the research;

(b) ability of academic staff to integrate research and teaching activities;

(c) tasks of research character in the curriculum;

(d) level of attracting students to the life of academic community of the department;

(e) level of formation of students' research culture;

(f) orientation at the development of research-oriented teaching approaches in policy of the chairs;

(g) measures of support and promotion of teacher's efforts in the development of research-oriented approaches to the organization of educational process in the department (Jenkins and Healey, 2005);

- development and audit of the university research policy, aimed at implementing the strategies of improving the links between research and educational work. Analyzed studies indicate the difficulties in solving the problem associated with the priority focus of universities on research activities that can bring the university significant financial support and high international status. However, there are enough examples of the insistence of university administration on the development of projects that have a positive impact on the educational process as a result of effective research activities;

- interconnection of educational and research work as a priority in the personnel policy of the university. Preparation for teaching is carried out in the universities in the framework of the master of doctoral studies of special courses that provide the acquisition of knowledge in the theory and methods of teaching in higher school. These programs are supported by university and national research centers, specializing in problems of the theory of higher education, for example, Higher Education Academy in the UK, National Science Foundation and Carnegie Foundation in the USA;

- organization of the system of events of research and educational character concerning research-oriented training programs. Organizational work in this direction is done by the structural units of universities, responsible for innovative activities and development of educational institutions in collaboration with the departments of educational and research work;

- effective cooperation in the activities of the administrative structures of the university, responsible for research and educational activities. Study of the experience of research universities around the world (the UK, the USA, Canada, Australia) suggests that in addressing the research problem is convincing the experience of the restructuring of traditional organizational structures, creating new ones that share responsibility for performing functions and are aimed at achieving synergy in the implementation of the leading components of the university mission. They include:

University policy determines the strategies that are implemented by the departments.

- attracting students to participation in the implementation of the institutional framework of integration of educational and research activities. Explaining to the students the benefits of learning in research-oriented environment, forming research culture of the student community is of strategic importance, since it contributes to a more conscious attitude towards the future professional development;

- audit of activities of the departments, which involves the implementation of strategies of research-oriented learning. It concerns the creation of special teams (teams of experts) in the university departments that develop support mechanisms of research-oriented learning. 
The subject of their work is the analysis of curricular policy of the department, in particular the content and structure of training programmes according to their compliance with the prospects of integration of educational and research activities in the mission of the university as a whole;

- display priorities of research-oriented learning in the requirements to the structure and content of curriculum. In the best universities, for example, in the University of British Columbia, the whole system of innovative approaches to the curriculum development is implemented, in particular introduction of flexible curriculum that implements the ideas of individual educational trajectories and self-organized learning; extension of interdisciplinary courses and the use of information technologies, namely MOOC-courses; creating by faculty and students joint research communities that share common research work and research culture; developing research-oriented learning environment, the existence of which is not limited by the territory of educational and laboratory buildings, but extends to the whole campus and outside - the global search space, and the like (UBC, 2015);

- interconnection between students' learning and research activities of university researchers. The analysis of studies shows that quite often the research structures of universities are not attracted to their educational programs. Overcoming negative practices help such steps of university administrators: (a) encouraging the heads of research units (centers, institutes, laboratories) to develop strategies to support curriculum of the subjects, that have innovative character;

(b) engaging research staff, leading specialists of the university research units in teaching courses according to their choice and guiding students' research projects;

(c) providing opportunities to the professionals who are engaged mainly in teaching, to participate in research projects carried out on the basis of relevant research units;

(d) encouraging the specialists of the university research units by the administration to inform teachers and students about their research results;

(e) establishing formal organizational links of the research community with students (UWM, 2015).

The priorities of the chairs in the implementation of the research-oriented teaching/ learning are the following:

- development of specialized training programs. Universities have a long experience of creating specialized research-oriented programs for each stage of study at the university. For example, in American universities are sufficiently developed inquiry-based projects for freshmen, which provide for the formation of students' research skills and fundamentals of research culture. In the USA there are national grant-giving organizations that support student research, even research of students studying for undergraduate programs. The example of such organization is Council on Undergraduate Research (Council on Undergraduate Research, 2011);

- positive evaluation and support of educational and research activities integration of teaching staff by the chair and criteria for making contract with them. Numerous studies of higher education development tendencies prove the growing impact of staff support policy on the institutional culture of the university. Traditionally in research universities the priority is given to the support policy of research activity, not the quality of teaching. However, more and more universities recognize that full realization of the mission requires the interrelated activity of teachers in research and teaching, resulting in implementing in the educational process the programs of innovative approaches support (including the grant). Besides deserves attention the discussion that a university teacher cannot be a "Jack 
of all trades", that is equally successful in all possible aspects of higher school activity. American researchers distinguish the following four areas of activity of a university specialist that have significant differences: research-experimental work; research-methodological work; consultation-expert work, teaching. Taking into account specialization of each faculty member in a particular field of activity and reasonable use of their strengths is recognized as a way that will enhance the effectiveness of training and activities of the chair, department and the university as a whole (Jenkins and Healey, 2005).

\section{CONCLUSIONS}

Thus, strategies of integration of educational and research activities in the professional training of specialists in the universities of developed countries have a multi-level multidimensional character and represent a holistic system of interrelated and interdependent components. The levels of implementation of such strategies and their subjects are: institutional (university), sub-institutional (educational and research departments of the university), chair. The systemic character of research-oriented strategies is achieved by an interrelation (synergy) of activities at all levels of implementation, and the inclusion of these strategies into the others, directed at increasing efficiency of educational process (development of Elearning, flexible curriculum, formation of a single university educational-research community, development of the university campus as a broad educational environment, etc.).

Thus, as the system of higher education in Ukraine is undergoing significant changes presently, further researches on specialists' professional training in developed countries are of great importance.

\section{REFERENCES}

1. Baldwin, G. (2005). The Teaching-Research Nexus: How research informs and enhances learning and teaching in the University of Melbourne. Melbourne : Centre for the Study of Higher Education, $11 \mathrm{p}$.

2. California Institute of Technology (CalTech). School mission and unique qualities. (2015). Retrieved 08.08.1015 from : colleges.usnews.rankingsandreviews.com/ best-colleges/cal-tech-1131.

3. Council on Undergraduate Research. (2011). Retrieved 08.08.2015 from : http://www.cur.org/.

4. de Weert, E. (2004). The Organisational Determination of the Teaching and Research Nexusin the 2004 Marwell Conference. Retrieved 01.08.1015 from: http://portallive. solent.ac.uk/university/rtconference/2004/resources/de_weert_paper.pdf.

5. Framework for Qualifications of the European Higher Education Area. (2005). Retrieved 08.08.1015 from : http://www.ecahe.eu/w/index.php/Framework_for_Qualificatio ns_of_the_European_Higher_Education_Area.

6. Harvard College. Mission, Vision and History. (2015). Retrieved 08.08.1015 from : https://college.harvard.edu/about/history.

7. Healey, M. (2010). Linking Research and Teaching: A selected bibliography. Retrieved 08.08.1015 from : http://www.mickhealey.co.uk.

8. Hénard, F. (2010). Learning Our Lesson : Review of Quality Teaching in Higher. Paris : OECD Publishing, 113 p. 


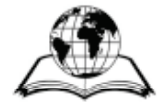

9. Jenkins, A., Healey, M. (2005). Institutional strategies to link teaching and research. London : The Higher Education Academy, 66 p.

10. Murphy, P., Peters, M., Marginson, S. (2010). Imagination: Three Models of Imagination in the Age of the Knowledge Economy. New York : Peter Lang, $401 \mathrm{p}$.

11. Robertson, J. (2007). Beyond the research/teaching nexus: exploring the complexity of academic experience. Studies in Higher Education, No 32 (5), pp. 541-556.

12. Trowler, P., Wareham, T. (2007). Reconceptualising the teaching-research nexus. Retrieved 08.08.1015 from : http://portal-live.solent.ac.uk/university/rtconference/ 2007/resources/paul_trowler.pdf.

13. University of British Columbia (UBC). The UBC Plan. Student Learning. (2015). Retrieved 06.08.1015 from : http//www.strategicplan.ubc.ca/the-plan/student-learning.

14. University of Cambridge (UC). The University's mission and core values. (2015). Retrieved 10.08.1015 from : https://www.com.ac.uk/about the university//how the university andcolleges-work/the-universitys-mission-and-core-values.

15. University of Western Australia (UWA). Teaching and Learning at UWA. (2015). Retrieved 08.08.1015 from : http//www.teachingandlearning.uwa.edu.au/teaching.

16. University of Wisconsin-Madison (UWM). Center for the Integration of Research, Teaching and Learning. (2015). Retrieved 08.08.1015 from : www.wcer.wisc.edu.

17. Wildavsky, B. (2010). The Great Brain Race: How Global Universities Are Reshaping the World. Princeton/Oxford : Princeton University Press, 248 p. 